\title{
CARACTERIZAÇÃO DE UMA UNIÃO SOLDADA DE AÇO INOXIDÁVEL DUPLEX*
}

\author{
Gabriel Grasselli Lorençon ${ }^{1}$ \\ Tarly Iselino Amorim Wengrat ${ }^{1}$ \\ William Haupt ${ }^{2}$ \\ Kauê Riffel ${ }^{3}$ \\ Charles Leonardo Israel ${ }^{4}$ \\ Paulo Henrique Sanchez Cardoso ${ }^{5}$
}

\section{Resumo}

Com a crescente utilização de aços inoxidáveis duplex na indústria petroquímica, química, de celulose e entre outras, motivada em grande parte pelas propriedades mecânicas e de resistência à corrosão apresentadas por estes materiais. Por se tratar de um material com altos teores de elementos de liga e ser composto por duas fases, ferrita e austenita, se faz necessário grandes cuidados na sua soldagem e um aprimoramento dos conhecimentos deste material quando submetido a este processo. Para tal, o presente trabalho denota um estudo da microestrutura de um aço inoxidável duplex após a sua soldagem pelo processo MIG pulsado, sendo aplicada uma energia durante a soldagem de $1,0 \mathrm{~kJ}$ e adotada uma temperatura entre os passes de soldagem de $150^{\circ} \mathrm{C}$. Também foram analisados os percentuais de ferrita e austenita, foi efetuada a contagem de fases do metal base e também da zona afetada pelo calor (ZAC). Foram encontrados na ZAC além da fase austenita secundária, uma fase intermetálica que possivelmente se trata de nitretos de cromo. Apesar do metal base estar com uma proporção ferrita/austenita aproximadamente igual, na ZAC houve um desbalanceamento entre as fases, onde a predominância foi de grãos de ferrita.

Palavras-chave: UNS S32205; Desbalanceamento de fases; Avaliação microestrutural; Fases intermetálicas.

\begin{abstract}
With the increasing use of duplex stainless steels in petrochemical, chemical, cellulose and among others, motivated in largely by the mechanical properties and corrosion resistance exhibited by these materials. Because its high content of alloying elements and by its microstructure constituted by two phases, ferrite and austenite, a great care is required in its welding and improvement of the knowledge of this material when subjected to this process. To this end, this paper denotes a study of the microstructure of a duplex stainless steel after welding by GMAW-P process, with an energy applied during welding $1.0 \mathrm{~kJ}$ and an interpass temperature under $150^{\circ} \mathrm{C}$. Also the percentage of ferrite and austenite were analyzed, it was made the phase count of base metal and also in the heat-affected zone (HAZ). Were found in the HAZ the secondary austenite phase, and an intermetallic phase that possibly is chromium nitrides. Although the base metal being with a ferrite/austenite approximately equal proportion, in the HAZ there was an imbalance between phases, where the prevalence was of ferrite grains.
\end{abstract}

CHARACTERIZATION OF A DUPLEX STEEL WELDED JOINT

Keywords: UNS S32205; Imbalance between phases; Microestructural evaluation; Intermetallic phases.

1 Engenheiro Mecânico, Acadêmico de Mestrado Profissional em Projeto e Processos de Fabricação, Universidade de Passo Fundo, Passo Fundo, Rio Grande do Sul, Brasil.

2 Engenheiro Mecânico, Mestre em Engenharia de Minas, Metalúrgica e de Materiais, Professor titular, Engenharia, Universidade de Passo Fundo, Passo Fundo, Rio Grande do Sul, Brasil.

3 Engenheiro Mecânico, Acadêmico de Mestrado, Departamento de Engenharia Mecânica, Universidade Federal de Santa Catarina, Florianópolis, Santa Catarina, Brasil.

4 Engenheiro Mecânico, Doutor em Engenharia de Minas, Metalúrgica e de Materiais, Professor universitário, Engenharia, Universidade de Passo Fundo, Passo Fundo, Rio Grande do Sul, Brasil.

5 Engenheiro Mecânico, Doutor em Engenharia de Minas, Metalúrgica e de Materiais, Professor universitário, Engenharia, Universidade Federal de Rio Grande, Rio Grande, Rio Grande do Sul, Brasil. 


\section{INTRODUÇÃO}

Aços inoxidáveis duplex, também conhecidos como aços inoxidáveis ferriticoausteníticos com a proporção entre fases de aproximadamente $50 \% \pm 5 \%$ [4], são ligas $\mathrm{Fe}-\mathrm{Cr}-\mathrm{Ni}-\mathrm{Mo}$, que contem nitrogênio na forma atômica. Sua microestrutura é composta por duas fases cristalinas, possuindo uma matriz ferrítica e austenita precipitada em forma de ilhas (Figura 1). Ambas as fases são obtidas através do processo de solubilização [2].

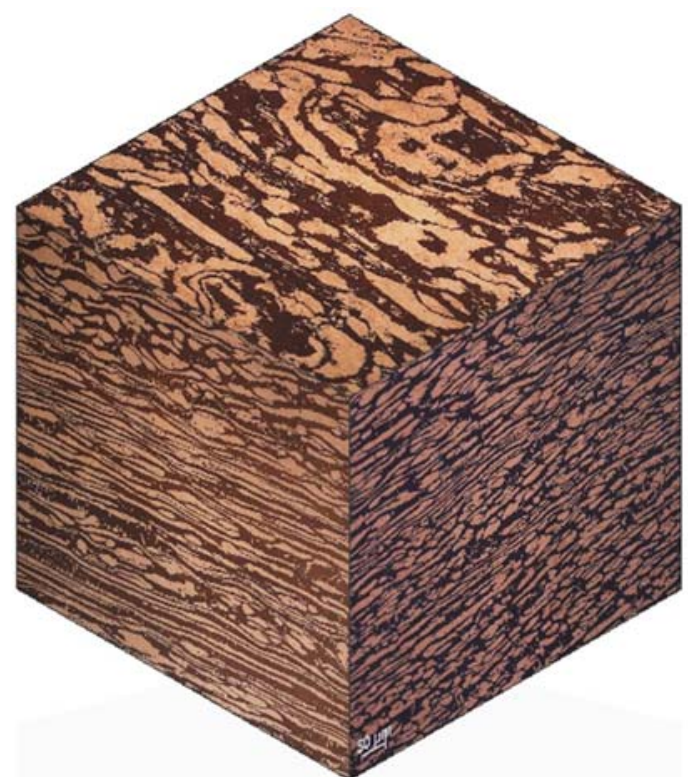

Figura 1. Metalografia típica de uma chapa laminada de aço inoxidável duplex.

Por possuírem uma excelente combinação de alta resistência mecânica, boa tenacidade e alta resistência a corrosão, estes aços vêm sendo amplamente utilizados na indústria de extração de petróleo nas plataformas "offshore" fixas ou flutuantes. São aplicados como componentes estruturais e também constituem componentes como por exemplo, peças fundidas.

Porém, quando se faz necessário que estes aços passem por processos que requerem altas temperaturas, inferiores a temperatura de $1.000^{\circ} \mathrm{C}$, pode ocorrer a formação de algumas fases intermetálicas, que acabam por prejudicar as propriedades do mesmo [2]. Um exemplo de fase intermetálica, é a austenita secundária $(\mathrm{\gamma} 2)$, que pode precipitar entre $650^{\circ} \mathrm{C}$ e $800^{\circ} \mathrm{C}$, seu principal efeito é a redução na resistência à corrosão do material.

Após a soldagem dos aços inoxidáveis duplex, dois problemas podem ocorrer, ambos aparecem durante o resfriamento da união soldada. O primeiro deles é o desbalanceamento das fases ferrita/austenita e o outro é a precipitação de fases intermetálicas na zona de fusão (ZF) e na zona afetada pelo calor (ZAC). O desbalanceamento das fases ferrita/austenita na ZAC pode ser visto na Figura 3, onde tem-se o ponto B (ZAC) que mostra este problema, devido a uma operação de soldagem inapropriada. 

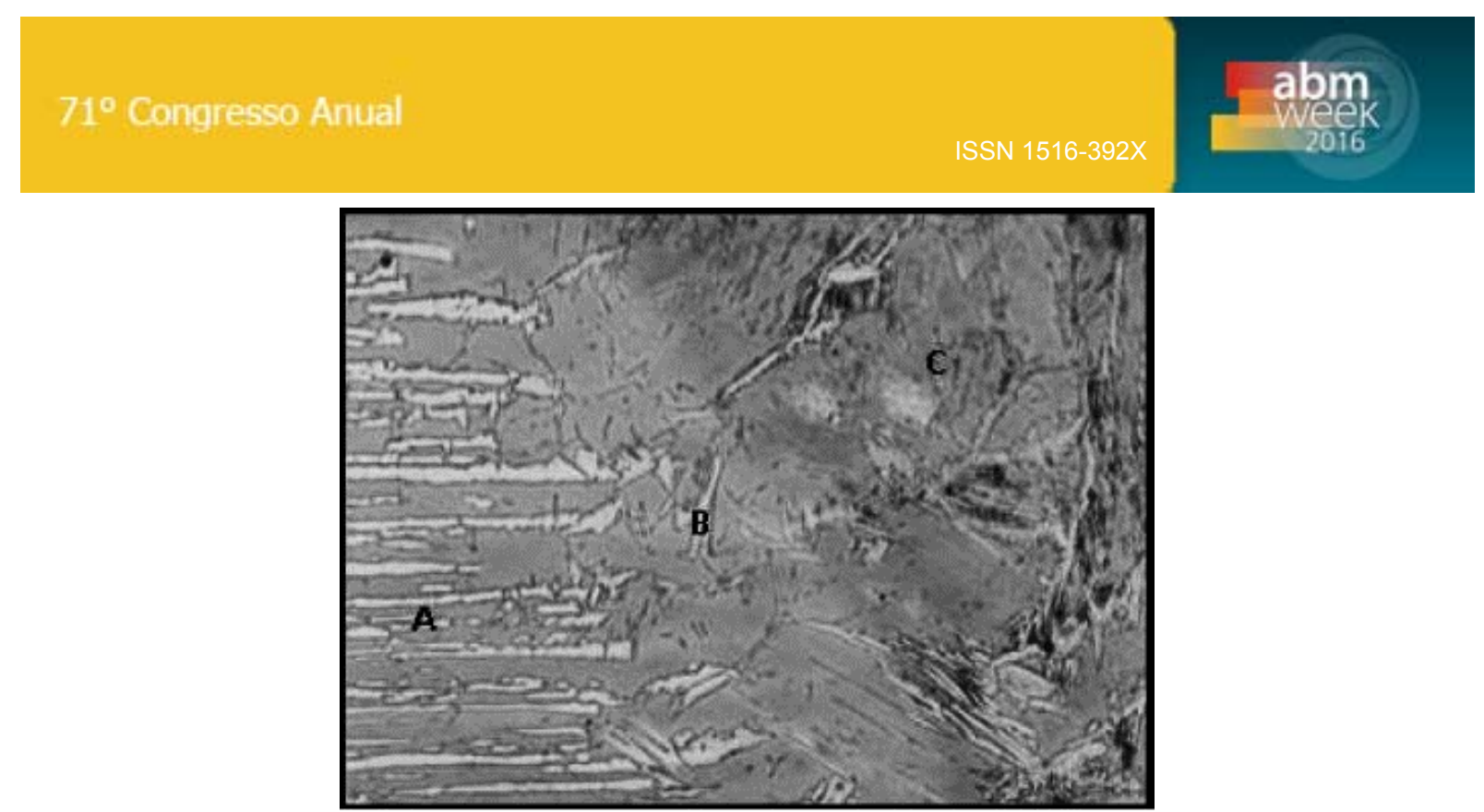

Figura 3. Exemplo de desbalanceamento entre as fases ferrita e austenita. Metal base (A); ZAC (B); Metal de adição (C). [8]

A qualidade de uniões soldadas de aços inoxidáveis duplex tem alguns critérios a serem atendidos, a microestrutura, as propriedades mecânicas e a resistência a corrosão. Além disto, deve-se dar atenção especial à proporção ferrita/austenita, à presença de carbonetos ou nitretos entre outros precipitados na ZAC. A fase intermetálica que mais precipita em uniões soldadas é a austenita secundária (Y2) [6].

Os processos de soldagem de aços inoxidáveis duplex mais utilizados são os processos TIG, soldagem a laser, soldagem a plasma, soldagem a arco submerso, MIG/MAG e soldagem a arco manual. O processo MIG/MAG pode ser com corrente contínua ou pulsado.

O fator determinante dos mecanismos de difusão e a transformação de ferrita, austenita e austenita secundária na ZAC é a curta exposição a altas temperaturas e o gradiente destas altas temperaturas. Também que a decomposição das fases primárias em fases secundárias tem forte influência na resistência à corrosão, dureza e resistência mecânica na ZAC [5]. Também existem diagramas TTT específicos que descrevem o tempo e a temperatura de evolução dos intermetálicos que podem precipitar [1].

A evolução da microestrutura do material depende dos campos térmicos induzidos durante o processo na zona de fusão e na ZAC, e tais campos dependem da fonte de aquecimento utilizada. Esta fonte de aquecimento, nestes processos é caracterizada por ser elevada e distribuída numa área relativamente grande da superfície [1]. Em consequência ao reaquecimento empregado durante o processo de soldagem ocorre a formação da austenita secundária (Y2) [9].

Por causa das fases intermetálicas que podem precipitar, em soldas de peças de espessuras relativamente grandes, onde se fazem necessário vários passes, é recomendada uma temperatura entre passes de aproximadamente $150^{\circ} \mathrm{C}$, pois temperaturas muito elevadas (entre $600^{\circ} \mathrm{C}$ e $1000^{\circ} \mathrm{C}$ ) podem precipitar outras fases intermetálicas mais prejudiciais à união soldada.

A utilização de um gás de purga na raiz, é necessária para que não haja corrosão no passe de raiz, uma boa proteção na raiz é essencial para minimizar a oxidação. É recomendado o uso de gás de purga durante o passe de raiz até o primeiro passe 
de enchimento na maioria dos casos. Ao soldar tubos, é benéfico reduzir o fluxo do gás após o passe de raiz, para que não seja criada uma sobre pressão. Também após cada passe, deve-se realizar a limpeza do cordão de solda, esta limpeza pode ser mecânica ou química [2].

\section{MATERIAIS E MÉTODOS}

Para este trabalho foi proposta inicialmente a caracterização metalúrgica do metal base, no caso um aço inoxidável duplex. O segundo passo foi realizar a soldagem do material, para em seguida realizar a caracterização metalúrgica da união soldada.

As chapas foram identificadas pela determinação da composição química através de espectrômetro de emissão óptica. Para caracterização do material, foram retiradas 3 amostras para que fossem realizadas as metalografias dos mesmos. As três amostras retiradas representam os três tipos de microestrutura que são encontradas em chapas laminadas, grãos alongados no sentido de laminação, que aparecem achatados em uma vista superior e cortados em uma vista transversal.

Estas amostras foram embutidas em baquelite para posterior lixamento utilizando as lixas $150,220,600,1200$ e 2500 . Em seguida, foi realizado o polimento das mesmas utilizando alumina $1 \mu$.

Por fim, as amostras foram atacadas utilizando o ataque químico Beraha modificado ( $80 \mathrm{~mL}$ de água destilada, $20 \mathrm{~mL}$ de $\mathrm{HCl}$ e $0,3 \mathrm{~g}$ de metabissulfito de potássio) com um tempo do ataque de 35 segundos. $O$ ataque Beraha modificado revela as fases ferrita e austenita.

Para visualizar as fases que compõem o material, foi utilizado o microscópio ótico Zeiss Scope A1. As imagens feitas no microscópio possibilitam a análise do material e realizar a contagem de fases do mesmo. O procedimento utilizado para contagem de fases foi seguido de acordo com a norma [7], a qual exige uma ampliação mínima de 400x para a contagem de fases.

A contagem de fases nas regiões do metal base e interface de soldagem foi realizada em imagens com ampliação de 500x, no software ImageJ®.

A soldagem do material foi realizada utilizando o robô de soldas instalado no Núcleo de Processos Mecânicos da Universidade de Passo Fundo.

O tipo de junta para solda escolhido para o trabalho, foi a junta do tipo "1/2 V com nariz", esta pode ser vista na Figura 4. O espaçamento na raiz utilizado, foi de $1,5 \mathrm{~mm}$.

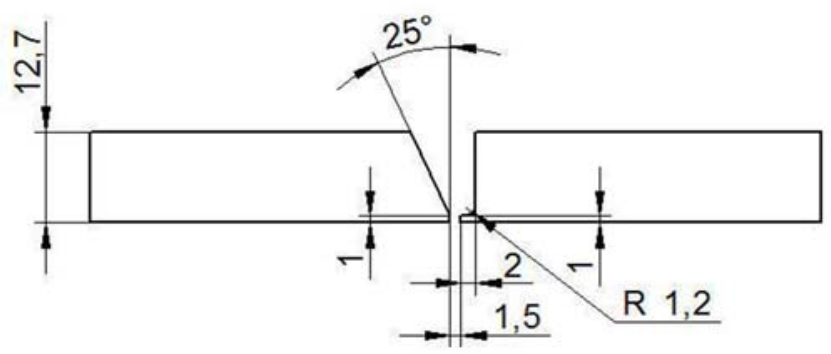

Figura 4: Junta do tipo "meio V com nariz". 
O bocal utilizado no processo de soldagem possuía $16 \mathrm{~mm}$ de diâmetro e eletrodo utilizado foi o ER2594L, 1,2mm de diâmetro. O gás de proteção utilizado no trabalho foi o $\mathrm{Ar}+2 \% \mathrm{CO}_{2}$. Também, como recomendado na bibliografia e pelos fabricantes de aços duplex, foi utilizado um gás de purga na raiz, no caso Argônio puro. A solda desta junta foi efetuada utilizando o processo MIG pulsado, que seguiu os parâmetros conforme a Tabela 1, a seguir.

Tabela 1: Parâmetros para passes de soldagem

\begin{tabular}{cc}
\hline \multicolumn{2}{c}{ Passe de Raiz } \\
\hline Corrente (A) & 130 \\
\hline Velocidade (cm/min) & 25 \\
\hline Energia (kJ) & 0,69 \\
\hline Passe de enchimento & \\
\hline Corrente (A) & 200 \\
\hline Velocidade (cm/min) & 30 \\
\hline Energia (kJ) & 1 \\
\hline
\end{tabular}

Para caracterização da união soldada, foi retirada uma amostra da seção transversal da junta soldada para a realização da metalografia. Após o embutimento, esta amostra foi lixada utilizando as lixas 150, 220, 600, 1200 e 2500. O ataque Beraha modificado foi utilizado novamente, porém com um tempo de ataque inferior de exposição, para verificação de fases intermetálicas o ataque foi efetuado por aproximadamente 5 segundos.

\section{RESULTADOS E DISCUSSÃO}

\subsection{Caracterização do Metal Base}

A composição química do material base está apresentada na Tabela 2. O material em questão é o aço inoxidável duplex UNS S32205.

Tabela 2: Composição química do metal base, \%.

\begin{tabular}{cccccccccc}
\hline $\mathbf{C}$ & $\mathbf{S i}$ & $\mathbf{M n}$ & $\mathbf{P}$ & $\mathbf{S}$ & $\mathbf{C r}$ & $\mathbf{M o}$ & $\mathbf{N i}$ & $\mathbf{C u}$ & $\mathbf{N}$ \\
\hline 0,031 & 0,341 & 1,504 & $<0,001$ & $<0,001$ & 22,79 & 3,186 & 5,199 & 0,137 & 0,168 \\
\hline
\end{tabular}

Na figura 5 pode-se notar grãos escuros e grãos claros, os grãos escuros são os grãos de ferrita ( $\alpha$ ), já os grãos claros são os grãos de austenita ( $\mathrm{Y})$. É apresentada uma vista tridimensional do material sendo possível verificar as direções de processamento do material. 

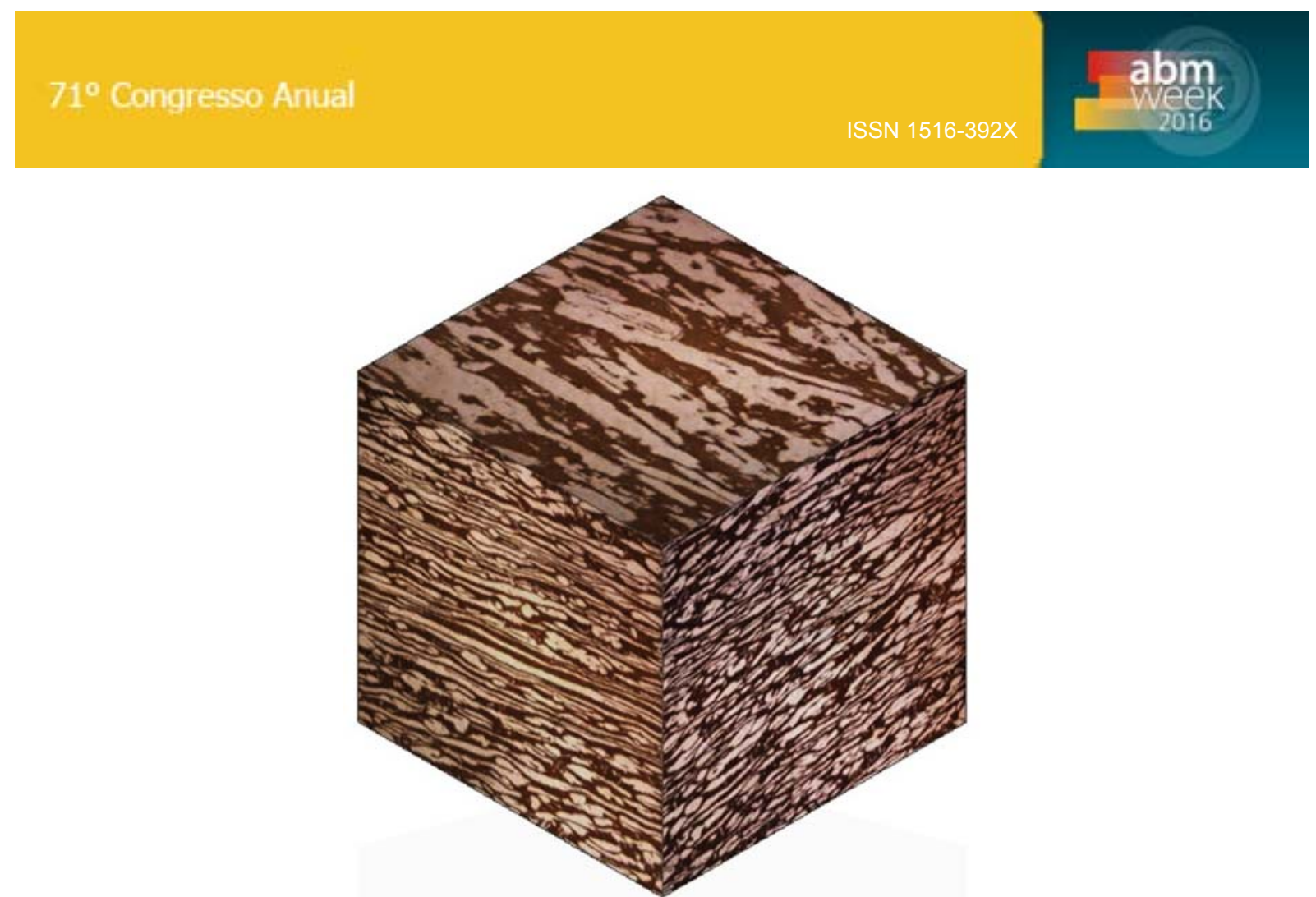

Figura 5: Microestrutura de uma chapa de aço inoxidável duplex. Ampliação 200x.

Em seguida, foram feitas imagens no microscópio ótico para que a contagem de fases fosse efetuada, para tal, a norma exige que as imagens tenham uma ampliação mínima de 400x, entretanto, as imagens foram capturadas utilizando uma ampliação de 500x.

Após obtidas as imagens, foi efetuada a contagem de fases de cada um dos sentidos da chapa, e por fim uma média das três medições para que fosse obtida a proporção estimada de ferrita/austenita, que pode ser vista no gráfico da Figura 6.

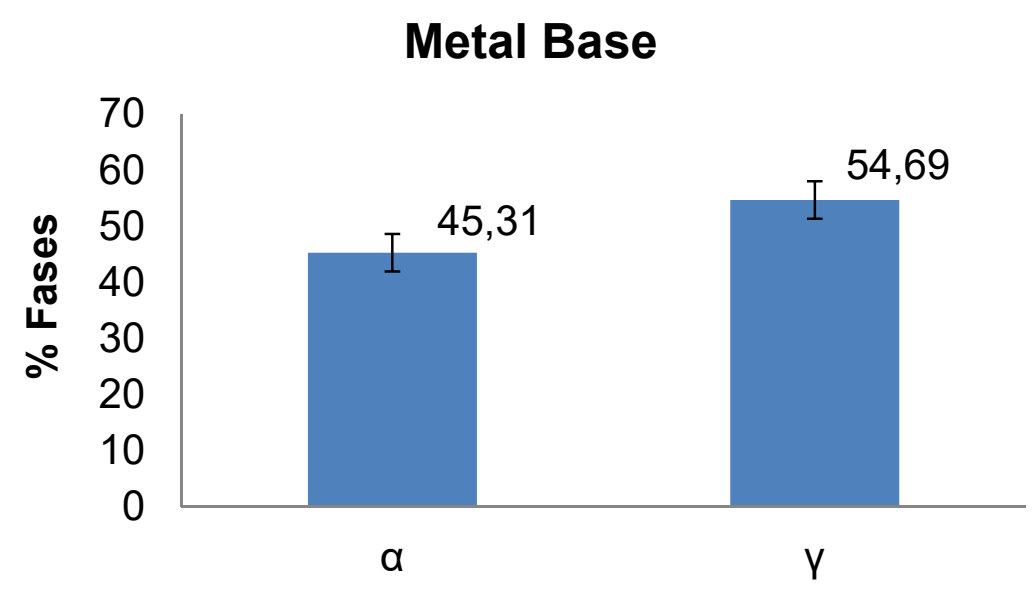

Figura 6: Média contagem de fases do metal base, \%.

Após realizar a contagem de fases em três locais diferentes do metal base, a média obtida das porcentagens é de aproximadamente $45,31 \%$ de ferrita, em consequência possui $54,69 \%$ de austenita. Com estas porcentagens de fases o material está dentro das proporções de $50 \% \pm 5 \%$ encontradas na literatura. 


\subsection{Caracterização da União Soldada}

Utilizando os mesmos procedimentos utilizados para realizar a metalografia do metal base foi realizada a metalografia da união soldada. Tal procedimento foi realizado com a finalidade de analisar a ZAC do material e identificar as fases intermetálicas que precipitaram.

A amostra foi atacada por imersão no reagente durante 10 segundos, para verificar se alguma fase intermetálica precipitada seria identificada com maior facilidade. Pode-se ver na Figura 7, a e b, que o ataque revelou, além do metal base e do metal de adição, a presença da fase austenita secundária $\left(\gamma_{2}\right)$, a região correspondente a ZAC também foi identifica nas figuras.

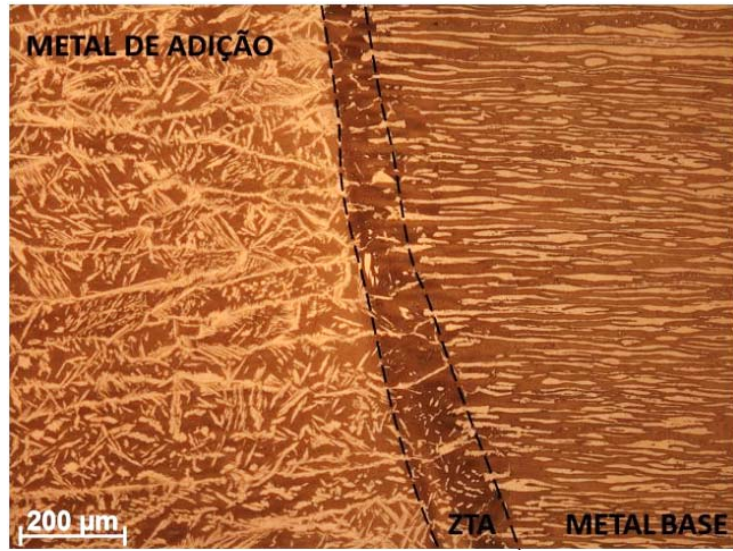

(a)

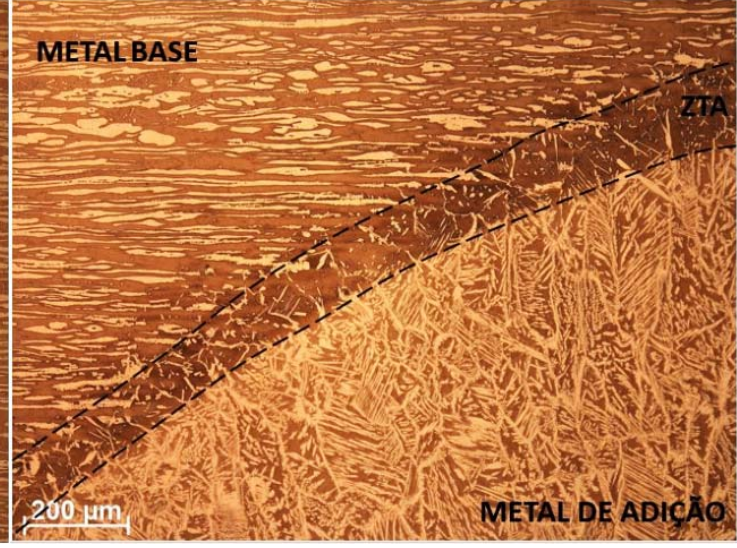

(b)

Figura 7: Metalografia da ZAC da união soldada. Ampliação 100x.

Como já é conhecido, a presença da austenita secundária reduz a resistência a corrosão por pite. Porém, outro detalhe que deve ser observado é que aparentemente, em algumas regiões ocorreu o desbalanceamento entre as fases ferrita e austenita.

Pode-se verificar melhor este fenômeno na Figura 8, onde utilizando uma ampliação de 500x pode-se identificar melhor as fases presentes na ZAC.

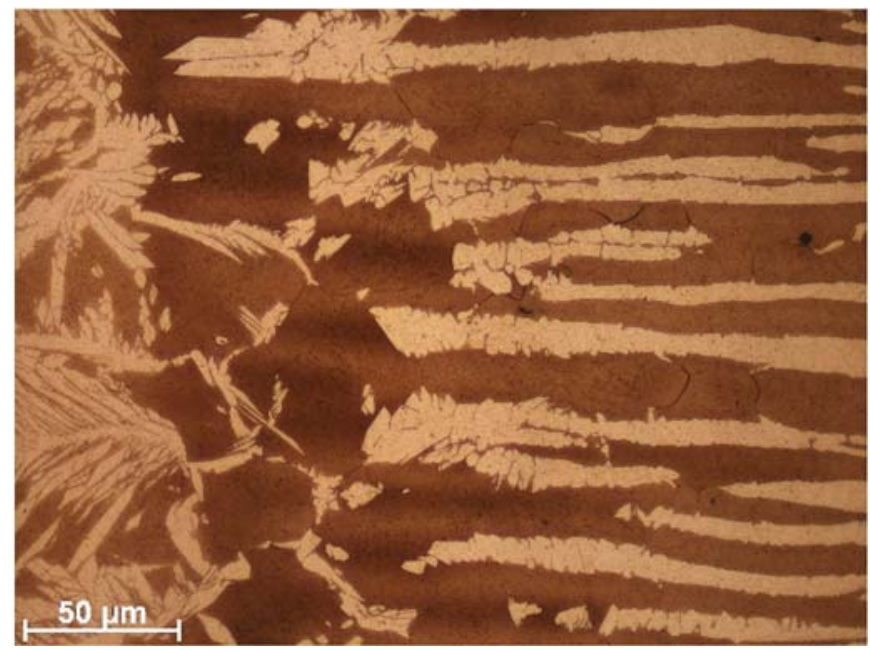

Figura 8: ZAC com maior quantidade de ferrita do que austenita. Ampliação 500x. 
Este desbalanceamento não ocorreu em toda a ZAC, apenas em alguns pontos, portanto ao aprimorar os conhecimentos sobre o processo de soldagem destes aços, será possível reduzir as áreas desbalanceadas.

A Figura 9 apresenta os valores de fases a e y para a interface de soldagem. É possível observar que houve modificação nos percentuais de fases devido ao ciclo térmico de soldagem, sendo observado um valor médio de $65,32 \% \pm 3,58 \%$ de $\alpha$ e $34,68 \% \pm 3,58 \%$ de $\gamma$.

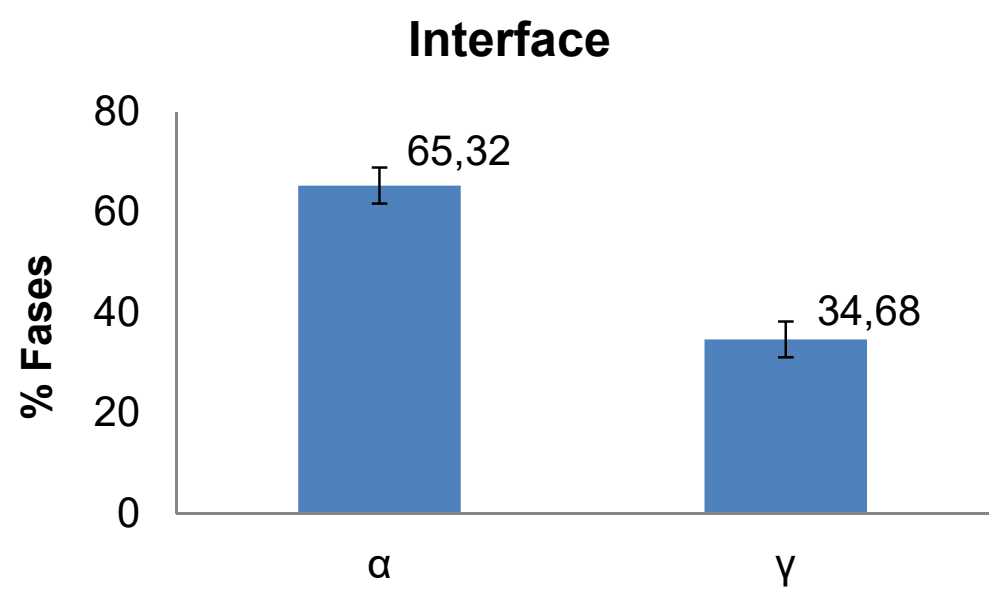

Figura 9: Média das contagens de fase da interface de soldagem, \%.

Outra fase intermetálica foi encontrada na amostra, provavelmente trata-se de nitretos de cromo. A Figura 10 mostra ambas as fases encontradas, a austenita secundária $\left(\mathrm{Y}_{2}\right)$, em branco, e os possíveis nitretos de cromo, os "pontos" pretos na amostra.

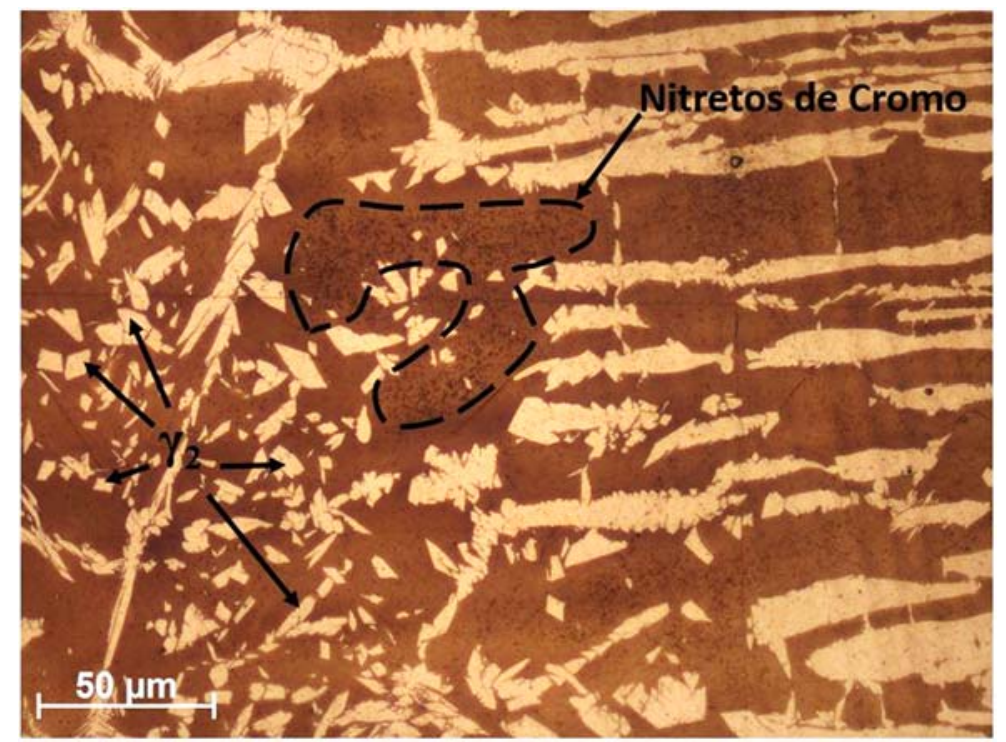

Figura 10: Fases intermetálicas $\bigvee_{2}$ e possíveis nitretos de cromo. 
O presente estudo teve como principal objetivo a caracterização da microestrutura de um aço UNS S32205 após soldagem pelo processo MIG pulsado. Este estudo permitiu as seguintes conclusões:

- Houve um aumento nos valores de ferrita junto à interface de soldagem, proveniente do ciclo térmico de soldagem. Estas modificações microestruturais podem reduzir as propriedades de corrosão e tenacidade das uniões nesta região.

- Foi observada a presença de fases intermetálicas na região ferritica da zona termicamente afetada, sendo a morfologia semelhante à de nitretos de cromo $\left(\mathrm{Cr}_{2} \mathrm{~N}\right)$ segundo a literatura. Também foi observada uma extensa formação de austenita secundaria na zona termicamente afetada. A formação destas fases pode prejudicar a resistência à corrosão nesta região.

\section{Agradecimentos}

Agradecemos a todos que colaboraram com o desenvolvimento do presente trabalho e em especial ao laboratório LAMEF do grupo GAF na Universidade Federal do Rio Grande do Sul em Porto Alegre que nos auxiliou no estudo e ao Paulo Henrique Sanchez Cardoso, doutor em Engenharia de Minas, Metalúrgica e de Materiais, pelo fornecimento das chapas. Também agradecemos ao Mestre William Haupt pela grande dedicação e apoio ao nosso estudo e similarmente ao nosso grande amigo e laboratorista Emerson Braz Ribeiro.

\section{REFERÊNCIAS}

1 Bonollo F, Tiziani A, Ferro P. Duplex stainless steels. Capítulo 4, Wiley. 2009.

2 Gunn RN. Duplex stainless steels - Microstructure, properties and applications. Abington Publishing. 1997.

3 Loureiro JP. Caracterização do aço inoxidável duplex UNS S31803 pela técnica não destrutiva de correntes parasitas. Escola Politécnica, Universidade Federal do Rio de Janeiro, 2010.

4 Martins M, Casteletti LC. Aços inoxidáveis duplex - Obtenção e caracterização.

5 Nowacki J, Lukojc A. Structure and properties of heat-affected zone of duplex steels welded joints. Journal of Materials Processing Technology. Páginas 1074 a 1081. 2005.

6 Nowacki J, Lukojc A. Microstructural transformations of heat-affected zones in duplex steel welded joints. Materials Chatacterization. Páginas 436 a 441. 2006.

7 Offshore Standard DNV-OS-F101. Submarine Pipeline Systems. 2013.

8 Samra Filho OA. Soldagem de componentes em aço inoxidável duplex e super duplex, aplicados nos módulos de plataformas de petróleo. Böhler Welding Group. 2012

9 Lippold, JC; Kotecki, DJ. Welding Metallurgy and Weldability of Stainless Steels. WileyInterscience. 2005. 